\title{
Patrice Delbourg, Max Jacob, un drôle de paroissien. Portrait
}

\section{Damiano De Pieri}

\section{(2) OpenEdition \\ Journals}

Edizione digitale

URL: http://journals.openedition.org/studifrancesi/934

DOI: 10.4000/studifrancesi.934

ISSN: 2421-5856

\section{Editore}

Rosenberg \& Sellier

\section{Edizione cartacea}

Data di pubblicazione: 1 agosto 2015

Paginazione: 403-404

ISSN: 0039-2944

\section{Notizia bibliografica digitale}

Damiano De Pieri, « Patrice Delbourg, Max Jacob, un drôle de paroissien. Portrait », Studi Francesi [Online], 176 (LIX | II) | 2015, online dal 01 août 2015, consultato il 18 septembre 2020. URL : http:// journals.openedition.org/studifrancesi/934; DOI : https://doi.org/10.4000/studifrancesi.934

Questo documento è stato generato automaticamente il 18 settembre 2020.

\section{(c) (i) (9)}

Studi Francesi è distribuita con Licenza Creative Commons Attribuzione - Non commerciale - Non opere derivate 4.0 Internazionale. 


\title{
Patrice Delbourg, Max Jacob, un drôle de paroissien. Portrait
}

\author{
Damiano De Pieri
}

\section{NOTIZIA}

PATRICE DelBourg, Max Jacob, un drôle de paroissien. Portrait, Bègles, Le Castor Astral, 2014, pp. 122.

1 Come indicato anche dal sottotitolo, l'agile libro di Patrice Delbourg è un vero e proprio ritratto letterario del poeta Max Jacob dove la progressione cronologica indispensabile in un'opera biografica è sostituita da un ordine di tipo tematico.

2 In nove brevi capitoli, con titoli che in parte richiamano l'humour noir implicito nel titolo del volume («Une métaphysique du coq-à-l'âne», pp. 11-31, «L'apparition», pp.33-39, «Une vie de bâton de chaise», pp.41-45, «Quimper...et passe», pp.47-51, «Grande parade verbale», pp. 53-57, «Le clown de Dieu», pp. 59-67, «L'ermite en sabot», pp. 69-75, «“J'ai ta peau”», pp.77-81, «Héritage du vent», pp. 83-92), l'A. traccia la vita del poeta facendo risaltare il carattere di un'esistenza e di un'opera in costante equilibrio funambulesque tra il tono comico e quello tragico, segnata da una parabola drammatica conclusasi con la morte nel campo di internamento di Drancy nel 1944. Un ritratto che sembra voler imitare l'ironia caratteristica dell'opera di Max Jacob attraverso uno stile disinvolto, discorsivo e a tratti molto colloquiale (un esempio appropriato, tra i tanti da citare, potrebbe essere l'espressione «l'aimable barde est bavard» con cui l'A. si riferisce al poeta). Il tutto infarcito di citazioni tratte da opere del poeta stesso e da testimonianze contemporanee, vere o presunte, di altre figure della modernità e delle avanguardie parigine senza nessuna pretesa di rigore documentaristico e biografico, né a maggior ragione scientifico. Infatti, come riportato nella nota che precede l'Indice, parte del testo è stata scritta per uno spettacolo di letture teatrali intitolato Max Jacob, sacré funambule. 
3 Sebbene Patrice Delbourg riesca a restituire la complessità di una figura spesso paradossale, ciò che alla fine si impone è la rappresentazione di una personalità stravagante ed eccentrica a discapito dell'immagine di un poeta originale e capace, la cui opera è stata determinante nel contesto letterario francese della prima metà del Novecento.

4 Il testo è completato da «Annexes» (pp.93-122) in cui a quattro poesie del poeta si succedono documenti iconografici, testimonianze di altri scrittori, una Cronologia essenziale e una Bibliografia. 